\title{
CONSERVAÇÃo Ex Situ DE RECURSOS GENÉTICOS DE PLANTAS NA REGIÃO TROPICAL ÚMIDA.
}

\author{
João Rodrigues de PAIVA ${ }^{1}$
}

\begin{abstract}
RESUMO - Nas duas últimas décadas, a Amazônia tornou-se foco de um processo de ocupação acelerado e desordenado, criando sérias preocupações quanto ao futuro de seu vasto patrimônio genético. A situação tende a se agravar à medida em que os métodos de conservação dos recursos genéticos, que ora são utilizados na Amazônia para manter coleções de plantas em campo, revelamse inapropriados. Além de onerosos e limitados à espécies de reconhecido valor econômico. Resultados de pesquisa evidenciam a importância de diversidade de espécies, densidade de plantas e variabilidade genética, como estratégias utilizadas pelas plantas para sobreviverem à heterogeneidade do ambiente tropical. Tomando-se como referência essas características, propõese discutir e apresentar um método de conservação ex silu de recursos genéticos de espécies autóctones da Amazônia.
\end{abstract}

Palavras Chaves: Amazônia, Germoplasma, Conservação, Ecossistema Tropical.

Conservation "Ex Situ" of Plantas Genetic Resources. In the Tropical Rain Region.

ABSTRACT - In the last two decades the Amazon region has been submitted to acelerated and disorganized development process that created serious worries about the future of its genetic resources. The situation has a tendency to aggravate because, at this time, there is no available ex situ conservation method for tropical species genetic resources. Some research works have shown the importance of species diversity, plant density and genetic variability as strategies utilized by the plants to survive in the heterogeneouness of the tropical ecossystems. This paper to discuss and present an ex situ genetic resources conservation method for autochthonous species in the Amazon region.

Key words: Tropical Ecossystems, Conservation, Genetic resources.

\section{INTRODUÇÃO}

A preocupação com os ecossistemas naturais é porque representam uma fonte imensurável de recursos genéticos de produtos de valor econômico. Grande parte desses recursos vem sendo destruídos antes do conhecimento de suas potencialidades.

Nas duas últimas décadas, a paisagem nativa de terra firme da bacia amazônica tem sido rápida e radicalmente transformada por ações de seres humanos. Pela expansão das rodovias e as fronteiras agrícolas, os grandes projetos hidrelétricos, os pólos minerais e de outras atividades, a floresta tropical densa vem sofrendo um processo intenso de desmatamento e fragmentação em grande escala. Em alguns Estados essa taxa se aproxima da exponencial (FEARNSIDE, 1986). Segundo KAGEYAMA (1987), a perda dos recursos genéticos não está limitada aos trópicos, mas o rítmo de desmatamento tem sido maior nas florestas de regiões tropicais e que, considerando a fragilidade desses ecossistema, também indica a prioridade que deve ser dada à

Centro de Pesquisa Agroflorestal da Amazônia Ocidental - CPAA/EMBRAPA, Caixa Postal 319, CEP 69.048-660, Manaus (AM). 
conservação nessas regiões, onde áreas protegidas são escassas e menos eficientemente cuidadas.

As atividades de coleta e conservação de recursos genéticos de plantas, constituem-se em atividades de pesquisa de alto custo e baixo retorno econômico a curto prấzo. Além disso, o desequilíbrio provocado pelo monocultivo, via de regra, compromete a conservação ex situ dessas plantas na região tropical úmida.

Pretende-se, nesta revisão, apresentar e discutir uma proposta de conservação de recursos genéticos de espécies vegetais, na forma de coleções de plantas mantidas a campo, a custos reduzidos. Para que o método funcione é necessário respeitar as características de cada espécie e manter o equilíbrio biológico com o ecossistema.

\section{REVISÃO DE LITERATURA}

\section{Coleta de Germoplasma} Autóctone

Na região Amazônica, habitat natural de inúmeras espécies vegetais de valor econômico atual e potencial, extensas áreas estão sendo desmatadas, principalmente nos Estados de Acre e Rondônia, no sul do Pará e norte de Mato Grosso. A substituição gradativa da vegetação natural condena ao desaparecimento inúmeras populações locais de espécies de valor genético imensurável.

A coleta e a conservação de germoplasma de espécies de plantas de valor econômico na Amazônia foram iniciadas pelo Instituto Agronômico do Norte (IAN), desde 1945, com a seringueira (Hevea spp). A partir de 1976, foram incrementadas pelo Centro Nacional de Pesquisa de Seringueira (CNPSe) (PAIVA, et al., 1986). A coleta de cacau (Theobroma cacao), Castanhado-Brasil (Bertholletia excelsa), caiaué (Elaeis melanococca, posteriormente $E$. oleifera), cupuaçu (Theobroma grandiflorum), guaraná (Paullinia cupana), pupunha (Bactris gasipaes), entre outras, também foi feita, desde 1962, pelo Instituto de Pesquisa e Experimentação Agropecuária do Norte (IPEAN), órgão que sucedeu ao IAN (ALBUQUERQUE \& LIBONATI, 1964).

A coleta de cacau também foi, logo a seguir, incrementada pela Comissão Executiva do Plano da Lavoura Cacaueira (CEPLAC), desde 1965 (BARRIGA et al., 1984).

A partir de 1975, as atividades de coleta e conservação das espécies citadas e de outras, principalmente de frutíferas, prosseguiram e foram incrementadas pelo Instituto Nacional de Pesquisa da Amazônia (INPA) e pelas seguintes Unidades da EMBRAPA: Centro Nacional de Pesquisa Seringueira e Dendê (CNPSD), Centro de Pesquisa Agropecuária do Trópico Úmido (CPATU) e Unidade de Execução de Pesquisa de Âmbito Estadual (UEPAE-Manaus) (CLEMENT et al., 1982).

\section{Conservação Ex Situ de Germoplasma}

A conservação da variabilidade genética existente em plantas na floresta tropical pode ser feita de duas maneiras: conservação in situ e conservação ex situ. Na conservação in 
situ as espécies são deixadas em seus habitats naturais, objetivando garantir proteção ao conjunto de genes das espécies e, quando necessário, preservar seu ecossistema inteiro.

Nesse caso, para que a conservação seja eficiente, é necessário conhecimento científico de biologia reprodutiva, ecologia, padrão de distribuição das espécies envolvidas, além de conhecimento prévio da existência de suficiente variabilidade genética nas populações das espécies envolvidas e de sua forma de distribuição, comparada a outras populações naturais.

A conservação ex situ refere-se à manutenção de genes ou complexos de genes em condições artificiais, fora do seu habitat natural. Este tipo de conservação pode ser feito em coleções permanentes de pólen, sementes, culturas de tecidos e coleções de plantas mantidas em campo.

Em alguns programas de melhoramento de espécies cultivadas, vêm se processando, gradativamente, a perda de variabilidade genética, devido principalmente ao pouco interesse em conservar material que não apresente características desejáveis, no atual estágio de desenvolvimento das técnicas de melhoramento inerente a cada espécie. Material considerado de pouca importância para os melhoristas hoje, poderá, no entanto, ser de grande utilidade no futuro.

Assim é que novas fontes de resistência às doenças são procuradas na natureza, visando introduzir maior variabilidade genética nos programas de melhoramento. A complexidade dos ecossistemas naturais das espécies arbóreas nas florestas tropicais dificulta o processo de coleta e conservação, por falta de suficiente conhecimento científico.

As espécies arbóreas possuem três características essenciais que devem ser consideradas no processo de conservação das coleções: a) geralmente as coleções são grandes e ocupam áreas muito extensas, dificultando a representatividade de cada tipo por um certo número de indivíduos; b) são de longo ciclo de vida, assegurando permanência e estabilidade no tempo; c) são espécies selvagens, predominantemente alógamas, que se estabilizam ocupando grandes áreas nos habitats naturais e possuem um alto grau de heterozigose, além de numerosos ecótipos que apresentam grandes diferenças (BOUVAREL, 1970).

O ambiente nos trópicos é extremamente favorável ao desenvolvimento de pragas e doenças que atacam as espécies, quando estão sendo cultivadas em monocultivo, principalmente, na região de ocorrência natural da espécie.

Os programas de melhoramento genético dessas espécies, objetivam, principalmente, resistência a doenças e aumento de produção. Para as culturas perenes o tempo de obtenção de uma nova cultivar é bastante longo, em contraste com as espécies de ciclo curto. Muitas vezes, um novo cultivar obtido é inviabilizado em um curto período de tempo, devido ao surgimento de uma nova raça do patógeno.

O aumento do nível de conhecimento dos ecossistemas naturais nos trópicos, obviamente terá implicações diretas, tanto nos processos de cultivos atualmente utilizados para as diferentes espécies, 
como nos programas de melhoramento genético, no que se refere à maior exploração da variabilidade existente nas espécies e, para tanto, é necessário que essa variabilidade esteja disponível.

A conservação da variabilidade genética de espécies autóctones, feita através de coleções mantidas a campo nos denominados bancos de germoplasma, vem sendo efetuada por várias Instituições de pesquisa da região (Tab. 1). Pelos dados existentes na literatura e informações de pesquisadores envolvidos com o problema, os resultados alcançados na manutenção dessas coleções são questionáveis. inviabilizou sua permanência na região.

\section{Ecossistema Tropical}

Existe um grande número de espécies arbóreas que ocorre nos trópicos. A maioria das espécies estudadas é conhecida taxonomicamente, mas pouco se sabe de sua ecologia, genética ou utilização pelo homem.

As árvores da floresta tropical úmida são de vida longa, apresentam características demográficas únicas e diversificados modos de reprodução. Além disso, outros estudos têm revelado que se caracteriza por apresentar grande diversidade de espécies, sistema predominante de polinização via animal; distribuição geográfica das plantas do tipo

Tabela 1. Números de acessos de espécies vegetais autóctones coletadas e conservadas na região Amazônica por Instituições de pesquisa.

\begin{tabular}{lccc}
\hline \multicolumn{1}{c}{ INSTITUIÇÕES } & N \% FAMÍLIAS & N \% ESPÉCIES & N ACESSOS \\
\hline CPATU & 14 & 29 & 85 \\
FCAP & 10 & 14 & 34 \\
INPA & 17 & 36 & 462 \\
CEPLAC & 1 & 6 & 1065 \\
UEPAE - Manaus & 1 & 1 & 130 \\
CNPSD & 1 & 5 & 479 \\
CNPSD & 1 & 1 & 343 \\
CPATU. & - & 75 & 1093 \\
\hline
\end{tabular}

CLEMENT et al., (1982); PAIVA et al., (1986); SANTOS et al., (1986); LIMA \& COSTA (1991).

Afora os problemas de natureza não técnica que, muitas vezes, provocam solução de continuidade no sistema de conservação, os problemas de ordem técnica são limitantes para certas culturas e de solução onerosa para muitas, devido ao desequilibrio biológico provocado pelo monocultivo. $\mathrm{O}$ constante ataque de pragas e doenças no BAG-Seringueira agrupado; e ecossistema com grande heterogeneidade ambiental (BAWA, 1974; BAWA \& OPLER, 1975; HAMRICK, 1983; KAGEYAMA, 1990). Essas características são fundamentais para que o nível de variabilidade, contido dentro das populações, tenha significado biológico importante para o equilíbrio do ecossistema (Tab. 2), 
Tabela 2. Diferenças entre algumas características de espécies arbóreas das florestas tropical úmida e temperada.

\begin{tabular}{lcc}
\hline \multicolumn{1}{c}{ CARACTERÍSTICA } & TROPICAL & TEMPERADA \\
\hline Sistema de reprodução & alógama & alógama \\
. Diversidade & grande & pequena \\
Densidade/ ha & menor & maior \\
Tipo de flor & hermafrodita & unissexual \\
. Tipo de polinização & animal & vento \\
Dispersão de sementes & animal & vento \\
Distribuição especial & agrupado & dispersa \\
. Fluxo gênico & menor & maior \\
. Heterogeneidade & maior & menor \\
ambiental & & rudimentar \\
Sistema de & desenvolvido & \\
autoincompatibilidade & &
\end{tabular}

A sucessão secundária é o mecanismo pelo qual as florestas tropicais se auto-renovam, através da cicatrização de locais pertubados (GOMEZ-POMPA, 1971). A morte natural ou acidental de uma ou mais árvores resulta em uma abertura no dossel da floresta, conhecida como clareira. As condições ambientais nestas clareiras são alteradas por aumento da quantidade de luz, da precipitação pluviométrica, da temperatura do ar e do solo e redução da disponibilidade de nutrientes e da umidade relativa (BAZZAZ \& PICKETT, 1980).

Naturalmente, as clareiras são recolonizadas por plantas de diferentes grupos ecológicos (classes de tolerância) de espécies árboreas. BUDOWSKI (1965) identifica quatro grupos de espécies: pioneiras, secundárias iniciais, secundárias tardias e climaxes. A principal característica de cada grupo está relacionada com a quantidade de luz requerida na fase de regeneração, onde as sementes das espécies pioneiras conhecidas pela sua intolerância à sombra - germinam apenas sob condições de alta temperatura e/ou luminosidade. Enquanto que as das espécies climaxes - também conhecidas como tolerantes à sombra - podem germinar e estabelecer suas plântulas nestas condições (Tab. 3).

Segundo WHITMORE (1978), o dossel de uma floresta muda continuamente conforme as árvores crescem, morrem e são substituídas, num estado dinâmico das três fases do ciclo de desenvolvimento de uma floresta: a fase de clareira, a de construção e a madura. Relata, ainda, que existe um mosaico dessas três fases na floresta tropical. A floresta pioneira, por sua vez, é arquiteturalmente homogênea; a floresta secundária tem uma arquitetura mais diversificada, com flora e fauna mais 
Tabela 3. Características de espécies arbóreas em diferentes estágios de sucessão.

\begin{tabular}{|c|c|c|c|c|}
\hline \multirow[t]{2}{*}{ CARACTERISTICA } & \multirow[t]{2}{*}{ PIONEIRAS } & \multicolumn{2}{|c|}{ SECUNDÁRIAS } & \multirow[t]{2}{*}{ CLÍMAX } \\
\hline & & INICIAIS & TARDIAS & \\
\hline $\begin{array}{l}\text { Idade da comunidade } \\
\text { (anos) }\end{array}$ & $2-5$ & $5-15$ & $20-50$ & $>100$ \\
\hline Altura (m) & $5-8$ & $12-20$ & $20-30$ & $30-45$ \\
\hline $\begin{array}{l}\text { Número de espécies } \\
\text { arbóreas }\end{array}$ & $1-5$ & $1-10$ & $30-60$ & $>10$ \\
\hline Tamanho de sementes & Menor & Menor & Menor & Menor \\
\hline Crescimento & Rápido & Rápido & Médio & Lento \\
\hline . Ciclo de vida (anos) & $<10$ & $10-25$ & $40-100$ & $>100$ \\
\hline . Tolerância à sombra & Intolerante & Intolerante & $\begin{array}{l}\text { Tolerante } \\
\text { (jovem) }\end{array}$ & Tolerante \\
\hline $\begin{array}{l}\text { Dispersão de } \\
\text { sementes }\end{array}$ & $\begin{array}{c}\text { pássaro, } \\
\text { vento, } \\
\text { morcego }\end{array}$ & idem & Vento & $\begin{array}{l}\text { Gravidade, } \\
\text { mamifero }\end{array}$ \\
\hline $\begin{array}{l}\text { Viabilidade da } \\
\text { semente }\end{array}$ & $\begin{array}{c}\text { Longa } \\
\text { (latência ) }\end{array}$ & Idem & Curta a média & Curta \\
\hline
\end{tabular}

Fonte: BUDOWSKI (1965)

ricas; a floresta clímax é a mais diversificada de todas.

As pesquisas com plantações mistas de espécies nativas vêm sendo conduzidas de longa data, porém a maioria não procura entender o papel das espécies quanto à sua função na floresta. Nesse caso, a sucessão secundária parece ser um conceito que permite melhor separar as espécies em grupos com características similares, principalmente, quanto ao grau de tolerância à sombra, em diferentes estádios de desenvolvimento das plantas, para seu uso em plantios mistos.

\section{Sistema Reprodutivo}

Do ponto de vista do melhoramento de plantas, as espécies são classificadas, quanto ao tipo de polinização, em dois grandes grupos: autógamas e alógamas.

As populações de plantas autógamas, geralmente, consistem de misturas de muitas linhagens homozigotas, estreitamente aparentadas, às quais, embora existindo lado a lado, permanecem mais ou menos independentes umas das outras.

Nas populações alógamas, todas as plantas são altamente heterozigotas e, quase sem exceção, a endogamia forçada resulta numa deterioração geral do vigor e em outros efeitos adversos (ALLARD, 1971). Assim, o tipo de sistema de cruzamento dentro de uma espécie tem um efeito maior sobre o padrão de variação que ocorre na espécie.

A discussão central sobre os sistemas reprodutivos das plantas tropicais tem sido a respeito do papel da endogamia e da heterogozidade, através da autofecundação e da 
polinização cruzada, respectivamente, na floresta e seus impactos sobre a especiação e a diferenciação das populações (BAKER, 1959; FEDOROV, 1966). Por isso, o objetivo de diversos estudos tem sido o de determinar se muitas espécies da floresta tropical são de autopolinização ou polinização cruzada (Tab. 4). reprodutivos na floresta tropical (BAWA \& OPLER, 1975; FRANKIE et al., 1976).

O conhecimento da biologia reprodutiva das espécies tropicais, incluíndo aspectos desde polinização e dispersão de sementes até o estabelecimento de novas plântulas, favorece o entendimento da distribuição da

Tabela 4. Biologia reprodutiva e formas de ocorrência de espécies arbóreas no Estado de São Paulo.

\begin{tabular}{ccccc}
\hline ESPÉcIES & $\begin{array}{c}\text { POLINIZADOR } \\
\text { (VETOR) }\end{array}$ & $\begin{array}{c}\text { DISPERSOR } \\
\text { DAS } \\
\text { SEMENTES }\end{array}$ & $\begin{array}{c}\text { FORMA DE } \\
\text { OCORRÊNCIA }\end{array}$ & $\begin{array}{c}\text { ESTÁGIO } \\
\text { SUCESSÃo }\end{array}$ \\
\hline $\begin{array}{c}\text { Bracatinga } \\
\text { (Mimosa } \\
\text { scabella) } \\
\text { Guarantã }\end{array}$ & Abelha (Pequena) & Gravidade & Agrupada & Pioneira \\
$\begin{array}{c}\text { (Esenbeckia } \\
\text { leiocarpa) } \\
\text { Juatobá }\end{array}$ & Mosca (pequena) & Gravidade & Agrupada & Clímax \\
$\begin{array}{c}\text { (Hymenaea } \\
\text { stilbocarpa) } \\
\text { Paineira }\end{array}$ & Morcego & Mamífero & Dispersa & Climax \\
$\begin{array}{c}\text { (Chorisia } \\
\text { speciosa) }\end{array}$ & Pássaro & Vento & Dispersa & $\begin{array}{c}\text { Secundária } \\
\text { tardia }\end{array}$ \\
\hline
\end{tabular}

Fontes: CATHARINO et al., (1982); CRESTANA et al., (1983): CRESTANA et al,, (1983/85).

A auto-incompatibilidade ocorre com bastante frequência nas espécies tropicais. É um mecanismo que evita a autofecundação das plantas, favorecendo o cruzamento e a troca de genes entre plantas da mesma espécie. No entanto, as espécies que possuem sistemas reprodutivos que favorecem o cruzamento entre plantas, podem apresentar um certo grau de endogamia, desde que o cruzamento seja entre plantas com um ancestral comum. Assim, torna-se evidente que a variação de fatores relacionados ao comportamento do polinizador e sua seleção podem ser importantes na evolução dos sistemas variabilidade genética nas populações naturais, o que é fundamental na orientação de coletas de recursos genéticos, principalmente no referente à definição do tamanho da amostra.

\section{Biologia da Polinização}

Devido ao calor, muitas espécies da floresta tropical apresentam maior proporção de florescimento noturno em relação às espécies de clima temperado. Nesse caso, os morcegos e as pequenas vespas são muito importantes como agentes polinizadores (BAKER et al., 1983). 
O período de tempo em que uma flor permanece viável para receber o pólen varia muito entre as espécies. As orquídeas epífitas, por exemplo, destacam-se pelo grande período em que as flores permanecem frescas; em contraposicão, as flores de algumas espécies de Passifloraceae permanecem viáveis apenas por algumas horas após a abertura (JANZEN, 1968). A antese ocorre em um determinado horário do dia ou da noite e é específica para cada espécie em processo de florescimento. No geral, as flores permanecem viáveis por um período de 24 horas.

O grau de autofertilização e de polinização cruzada em plantas visitadas por insetos depende consideravelmente da atividade dos polinizadores.

O exercício da polinização executada por insetos é feito mediante uma recompensa, representada por néctar e pólen. $\mathrm{O}$ inseto recebe o pagamento da recompensa mediante a pronta entrega do pólen de outra planta. Por isso, o comportamento do polinizador é influenciado pela variação temporal da recompensa.

Para atrair os insetos polinizadores as plantas utilizam vários recursos: coloração, forma e perfume das flores; produção de néctar; além do próprio pólen. Normalmente, esses atrativos são utilizados pela planta em conjunto (BAKER, 1978).

De um modo geral, ao chegarem em uma determinada planta, os insetos visitantes passam por muitas flores antes de se dirigirem a outra planta. A tranferência de pólen de uma flor para outra dentro da mesma planta, com a consequente fertilização do óvulo, é chamada de geitonogamia (BAKER et al., 1983).

Em contrapartida, a autogamia, que consiste na trasferência de pólen até o estígma da mesma flor, seguido da fertilização, pode ocorrer com ou sem assistência do polinizador. Geneticamente, os efeitos da geitonogamia e autogamia são semelhantes, com exceção de algum raro caso, onde diferentes partes da copa de uma árvore podem diferir geneticamente devido aos efeitos de mutação somática (BAWA, 1974).

Em espécies monóicas têm-se, separadamente, a formação dos gametas masculinos e femininos na mesma planta. A polinização cruzada, por causa disso, é obrigatória, porém existe também a possibilidade de ocorrer a geitonogamia.

Embora muitas espécies da floresta tropical possuam mecanismos de auto-incompatibilidade, esses podem não serem completos,possibilitando, portanto, a ocorrência de autofecundação ou polinização cruzada dentro da mesma planta (BAWA, 1974; GAN et al., 1977).

A porcentagem de autofecundação ou cruzamento, que acontecem em plantas na floresta tropical, pode variar em função do clima e da disponibilidade do polinizador, além da dispersão das plantas, considerando uma espécie em particular dentro da faixa de vôo do polinizador. Portanto, torna-se difícil medir a taxa de cruzamento para muitas espécies tropicais. 
O período de tempo em que uma flor permanece viável para receber o pólen varia muito entre as espécies. As orquídeas epífitas, por exemplo, destacam-se pelo grande período em que as flores permanecem frescas; em contraposicão, as flores de algumas espécies de Passifloraceae permanecem viáveis apenas por algumas horas após a abertura (JANZEN, 1968). A antese ocorre em um determinado horário do dia ou da noite e é específica para cada espécie em processo de florescimento. No geral, as flores permanecem viáveis por um período de 24 horas.

O grau de autofertilização e de polinização cruzada em plantas visitadas por insetos depende consideravelmente da atividade dos polinizadores.

O exercício da polinização executada por insetos é feito mediante uma recompensa, representada por néctar e pólen. $\mathrm{O}$ inseto recebe o pagamento da recompensa mediante a pronta entrega do pólen de outra planta. Por isso, o comportamento do polinizador é influenciado pela variação temporal da recompensa.

Para atrair os insetos polinizadores as plantas utilizam vários recursos: coloração, forma e perfume das flores; produção de néctar; além do próprio pólen. Normalmente, esses atrativos são utilizados pela planta em conjunto (BAKER, 1978).

De um modo geral, ao chegarem em uma determinada planta, os insetos visitantes passam por muitas flores antes de se dirigirem a outra planta. A tranferência de pólen de uma flor para outra dentro da mesma planta, com a consequente fertilização do óvulo, é chamada de geitonogamia (BAKER et al., 1983).

Em contrapartida, a autogamia, que consiste na trasferência de pólen até o estígma da mesma flor, seguido da fertilização, pode ocorrer com ou sem assistência do polinizador. Geneticamente, os efeitos da geitonogamia e autogamia são semelhantes, com exceção de algum raro caso, onde diferentes partes da copa de uma árvore podem diferir geneticamente devido aos efeitos de mutação somática (BAWA, 1974).

Em espécies monóicas têm-se, separadamente, a formação dos gametas masculinos e femininos na mesma planta. A polínização cruzada, por causa disso, é obrigatória, porém existe também a possibilidade de ocorrer a geitonogamia.

Embora muitas espécies da floresta tropical possuam mecanismos de auto-incompatibilidade, esses podem não serem completos,possibilitando, portanto, a ocorrência de autofecundação ou polinização cruzada dentro da mesma planta (BAWA, 1974; GAN et al., 1977).

A porcentagem de autofecundação ou cruzamento, que acontecem em plantas na floresta tropical, pode variar em função do clima e da disponibilidade do polinizador, além da dispersão das plantas, considerando uma espécie em particular dentro da faixa de vôo do polinizador. Portanto, torna-se difícil medir a taxa de cruzamento para muitas espécies tropicais. 


\section{Dispersão de Sementes}

A diversidade de formas, cores, sabores e odores dos frutos tropicais são estratégias utilizadas pelas espécies para atrair os dispersores e, com isso, facilitar o fluxo de genes entre plantas na população.

A dispersão de sementes é uma parte essencial do processo reprodutivo. Está intimamente relacionada à distribuição espacial das espécies no seu habitat natural e, de certa forma, tem implicação direta com a distribuição da variabilidade genética na floresta. No entanto, em muitas espécies foi verificado que ocorre seleção para caracteres que reduzem a dispersão. Como exemplo, no oeste africano, ocorre na espécie Ceiba pentranda a seleção de plantas com frutos que não se fendem quando maduros, dificultando o processo de germinação da semente e estabelecimento de novas plantas (BAKER, 1965).

Os mecanismos de dispersão de sementes na floresta tropical envolvem vento, água e animais. São denominados dispersões abiótica e biótica. O processo, no todo, inclui o transporte da semente da planta até o solo, no espaço compreendido fora da projeção da copa ou das raízes, até o estabelecimento das novas plântulas. Segundo JANZEN (1980), semente caída embaixo da planta-mãe não é considerada como dispersa.

A dispersão de sementes, conforme WHEELWRIGHT \& ORIANS (1982), teria um padrão de evolução um tanto diferente em relação à dispersão de pólen pelas plantas, devido ao estímulo para alcançar o objetivo. No caso das sementes, a recompensa é "a priori", durante o evento, fazendo com que a pressão de seleção seja menos dependente entre a planta e o dispersor. Embora a grande variedade de formas, cores, consistências e sabores das frutas tropicais sejam fatores determinantes para uma certa redução do número de dispersores, geralmente, não limitados a uma só espécie.

A dispersão pelo vento, comparada aos outros mecanismos, oferece a vantagem de a planta gastar menor quantidade de energia na produção de sementes, por apresentarem características que facilitam a dispersão: geralmente são pequenas, leves e aladas. Conforme JANZEN (1980), as famílias lenhosas tropicais parecem ter sofrido evolução no sentido de suas sementes serem dispersas pelo vento.

A ecologia de dispersão tem demonstrado ser uma importante ferramenta para análise de estrutura e funcionamento das comunidades tropicais. Por outro lado, a diversidade da floresta tropical depende não só dos mecanismos de dispersão, mas também é fortemente influenciada pela comunidade de herbívoros (JANZEN, 1973).

A composição florística das áreas inundáveis é influenciada pelo regime de inundações. A água dos rios é o meio de transporte de sementes de um grande número de espécies de plantas, a qual, também, influencia nas condições de crescimento de determinadas espécies e na evolução dos diferentes agrupamentos botânicos. 
A dispersão tem um grande significado no controle e manutenção da diversidade biótica, como um pré-requisito para a existência e a continuidade do sistema tropical.

\section{Diversidade de Espécies}

Nos ecossistemas tropicais, conforme vai diminuindo a latitude $\mathrm{e}$ aumentando o gradiente térmico-úmido, o número de espécies nas diversas comunidades vai aumentando até atingir um ponto máximo nas florestas tropicais úmidas (Tab. 5). No geral, essas florestas se caracterizam por apresentar um grande número de espécies por unidade de área, representadas por poucos indivíduos de cada espécie - comumente em torno de 300 espécies arbóreas por hectare e, algumas vezes, acima de 500 indivíduos por hectare, como na floresta amazônica (KUBITZKI, 1985).

Os ecossistemas tropicais, sem dúvida, apresentam maior diversidade de espécies e maior complexidade nas interrelações entre indivíduos. A grande diversidade tem origem em diversas hipóteses, propostas por inúmeros autores, incluíndo-se: predação de sementes, mosaico de nutrientes, redes circulares, heterogeneidade temporal, entre outras (PIANKA, 1983).

A diversidade é resultante da somatória de muitos fatores interagindo no ecossistema. Como consequência, os indivíduos de uma espécie ficam isolados entre outros de espécies diferentes, havendo implicações na dinâmica da floresta em termos de interação planta $x$ animal, os quais são independentes e bem coadaptados, dando integração e estabilidade ao ecossistema.

Portanto, para que haja maior adaptação das espécies para sobreviver às condições reinantes nos ambientes tropicais, é necessário também haver diversificação entre indivíduos. ODUM (1975) ressaltou as vantagens da diversidade de espécies, com implicações no valor da sobrevivência para a comunidade, o qual consiste de uma maior estabilidade.

Tabela 5. Número de espécies arbóreas em diferentes ecossistemas naturais.

\begin{tabular}{llcl}
\hline \multicolumn{1}{c}{ ECOSSISTEMA } & \multicolumn{1}{c}{ LOCAL } & $\begin{array}{c}\text { No DE } \\
\text { ESPÉCIES }\end{array}$ & \multicolumn{1}{c}{ FONTES } \\
\hline Floresta de coníferas & $\begin{array}{l}\text { Michigan (USA) } \\
\text { Novo León } \\
\text { (México) }\end{array}$ & 10 & SPURR \& BARNE (1982) \\
Floresta de patula & 27 & VELA (1980) \\
Cerrados & $\begin{array}{l}\text { Brasília (Brasil) } \\
\text { Panamá }\end{array}$ & 82 & OAKI \& SANTOS (1982) \\
Floresta Tropical & $\begin{array}{l}\text { KNIGTH (1971) } \\
\text { São Paulo } \\
\text { (Brasil) } \\
\text { Floresta Subtropical }\end{array}$ & 189 & $\begin{array}{l}\text { BAITELLO \& AGUIAR } \\
\text { (1982) }\end{array}$ \\
Floresta Tropical & $\begin{array}{l}\text { Amazil) } \\
\text { (Brasil) } \\
\text { Amazonas } \\
\text { (Brasil) }\end{array}$ & 265 & ROSOT et al., (1982) \\
Floresta Tropical & 310 & SCHUBART (1983) \\
\hline
\end{tabular}


Por outro lado, o ambiente tropical permite alta taxa de evolução, diversificação e especiação, devido à reprodução rápida e contínua e à intensiva seleção natural. Por isso, deve haver uma substancial contribuição à diversidade. Segundo BROWN (1987), as regiōes de maior heterogeneidade no ambiente permitem uma acomodação de uma parte maior dessa diversidade potencial.

É evidente que a diversidade de ambiente que existe na floresta tropical, de certa forma, determina a existência de diversidade nas populações de plantas. Além do que as perturbações que ocorrem no meio também provocam alterações nessas populações, no sentido de atingir um novo equilíbrio. A manutenção do equilíbrio também depende da existência de complexas interações entre as plantas e o meio.

\section{Densidade de Plantas}

Quando se estuda a densidade de plantas de uma espécie em seu local de ocorrência natural é comum inferir-se que, quanto mais baixa for essa relação, maior é o nível de problemas biológicos relacionados com a espécie. Por exemplo, a relação existente para a seringueira (Hevea brasiliensis) em populações naturais é de 4-6 plantas por hectare. No entanto, a seringueira cultivada na região apresenta um condicionante biológico, relacionado à doença das folhas, causada pelo fungo Microcyclus ulei, que inviabiliza seu cultivo na densidade recomendada de 476 plantas/ha (espaçamento de $7 \mathrm{~m} \times 3 \mathrm{~m}$ ).

Para ocorrer o fluxo gênico, entre e dentro de populações naturais, é necessário que a espécie mantenha interação com o meio ambiente. A manutenção dessa interação é condição necessária para haver equilibrio di espécie com o meio ambiente. O equilíbrio é manifestado pelas plantas que conseguem sobreviver, mesmo num ambiente favorável ao aparecimento de doenças. Isso ocorre porque a floresta tropical caracteriza-se por apresentar baixa densidade de plantas de uma mesma espécie por hectare.

KAGEYAMA et al., (1992) referem-se à riqueza do ecossistema tropical como sendo devida a frequência de espécies raras que ocorrem em baixa densidade, com menos de um indivíduo por hectare. Levantam, ainda, hipóteses de que esse grupo de plantas tem um polinizador específico, sofre uma seleção dependente da frequência e tem um sistema de reprodução alternativo.

O cultivo de espécies autóctones na região, via de regra, desrespeita as características básicas que as mantém em suas populações naturais. Essas características - alta diversidade e baixa densidade - são responsáveis, em parte, pela manutenção do equilíbrio biológico existente nas populações.

O monocultivo, por exemplo, normalmente nâo atende a esses requisitos e conduz à uniformidade, na expectativa do aumento da produtividade. Em qualquer ambiente, a uniformidade do material genético expõe o plantio a riscos de perdas, devido ao surgimento de novas pragas e/ ou doenças. Nas regiões tropicais, a uniformidade inviabiliza a manutenção da atividade agrícola, em decorrência de um processo biológico mais dinâmico. Por isso, pode-se afirmar que "o progresso conduz à uniformidade e a uniformidade 
conduz ao fracasso" (PATERNIANI, 1988).

\section{Variabilidade Genética}

A diversidade genética, ou variabilidade devido a diferenças nos alelos, conforme relata KAGEYAMA (1987), pode ocorrer em diferentes níveis: a) de espécies dentro de ecossistemas; b) de populações dentro de espécies e c) de indivíduos dentro de populações de espécies. Essa caracterização também é necessária para a compreensão dos padrões de distribuição da variabilidade genética existente em populações naturais na floresta tropical.

A distribuição da variabilidade genética natural é influenciada por fatores como: a) modo de reprodução; b) sistema de cruzamento; c) tamanho efetivo da população; d) distribuição geográfica; e) estágio na sucessão; e f) fluxo gênico, expresso pela migração ou emigração de pólen e semente em uma população (HAMRICK, 1983).

Normalmente, uma população para sobreviver e persistir no tempo deve encontrar-se adaptada ao solo e ao meio em que vive, como também ter condições de adaptação às mudanças que podem ocorrer em seu ambiente, características que são favorecidas por alguns dos meca-nismos promotores de variabilidade, tais como mutação e recombinação (KAGEYAMA \& PATIÑNO-VALERA, 1985).

A fecundação cruzada representa um fator altamente positivo, baseado na maior variabilidade genética produzida pelos constantes intercâmbios e recombinação genética entre os indivíduos heterozigotos
(FAEGRI \& PIJL, 1976). Esses resultados são corroborados pelos estudos de BAWA (1974), que demonstrou haver predominância de alogamia nas florestas tropicais.

HAMRICK (1983) relaciona a efetividade da distância de vôo do polinizador com a distribuição da variação genética entre e dentro de populações de espécies arbóreas polinizadas por animais, sugerindo padrões de variação próximos aos das espécies autógamas para aquelas cujos polinizadores são de vôos curtos; até padrões similares aos das espécies alógamas, com dispersão de pólen pelo vento, para aquelas que têm polinizadores de vôos longos.

Do mesmo modo, KAGEYAMA \& PATIÑO-VALERA (1985) formularam a hipótese de que a distribuição espacial dos indivíduos de uma espécie está interligada intimamente ao tipo de polinização e de dispersão de sementes dessa espécie. Assim, existiria um continuum de gradação, desde espécies arbóreas com distribuição agrupada associada a polinizadores e dispersores de vôos curtos, até àquelas com distribuição muito dispersa, associadas a polinizadores e dispersores de vôos longos. Nesse contexto, os padrões de fluxo gênico, através da dispersão de pólen e semente, parecem fortemente relacionados com os padrões de variação genética nas populações.

A complexidade dos ecossistemas naturais das espécies arbóreas nas florestas tropicais é indicativo de que os estudos sobre estimativas de variação genética em populações 
naturais, devem orientar-se para a quantificação da variação entre e dentro de populações.

Esses conhecimentos são adquiridos a partir de informações básicas sobre a biologia reprodutiva, forma e padrão de distribuição da espécie e das estimativas de variâncias fenotípicas e genotípicas.

\section{MÉTODOS DE CONSERVAÇÃO Ex Situ}

\section{Combinando diversidade, densidade e variabilidade}

O aproveitamento racional da variabilidade genética das espécies cultivadas na região tem sido modesto, comparativamente ao seu potencial. Todavia, à medida que novos conhecimentos vêm sendo adquiridos sobre a forma de organização, manutenção e distribuição da variabilidade genética das espécies tropicais, se fortalece a hipótese de que o cultivo de uma espécie em ambiente tropical tem que, obrigatoriamente, permanecer em equilíbrio com os fatores bióticos e abióticos do ecossistema. Caso contrário está fadado ao insucesso.

Associado a necessidade imediata de incrementar a coleta de recursos genéticos em populações de espécies autóctones, sob risco de erosão genética, primeiramente é necessário viabilizar a conservação $e x$ situ para evitar perdas indiscriminadas de variabilidade genética, existente nas coleções de plantas mantidas em campo.
Tomando-se como referência algumas características que contribuem para manutenção do equilíbrio entre as espécies e o meio ambiente, apresenta-se um método de conservação ex situ de recursos genéticos de plantas, que seja mais apropriado a região tropical úmida e reproduza o equilíbrio das populações naturais.

A hipótese é implantar e avaliar sistemas que combinem diversidade de espécies, densidade de plantas de uma mesma espécie por hectare e variabilidade genética dentro das espécies, para viabilizar a conservação de germoplasma na região Amazônica, na forma de coleções mantidas a campo, com custos reduzidos e respeitando-se as características de cada espécie.

Em linhas gerais, no modelo de conservação proposto avalia-se o comportamento de 12 espécies, sendo 5 florestais dominantes e 7 de fruteiras, por hectare. São utilizados 3 tipos de espaçamentos: i) 4 espécies no espaçamento $20 \mathrm{~m} \times 5 \mathrm{~m}$; ii) 3 espécies em $10 \mathrm{~m}$ x $10 \mathrm{~m}$; e iii) 5 espécies em $50 \mathrm{~m} \times 10 \mathrm{~m}$. No arranjo espacial utilizado 6 espécies ficam com densidade de 80 plantas/ha, 5 com 20 plantas/ha e 1 (uma) com 64 plantas/ha, totalizando 644 plantas/ha.

$\mathrm{Na}$ falta de informações sobre o comportamento das espécies nas populações naturais, admite-se que algumas delas suportam diferentes níveis de sombreamento, apesar de cultivadas na região a "pleno sol". Presume-se que a sobrevivência às condições do modelo serão das espécies cujas características estejam nele representadas.

Desse modo, foram coletadas 
sementes das seguintes espécies: seringueira (Hevea spp) - rodovia AM 010, Manaus (AM); caroba ou pará-pará (Jacanda copaia) - reserva Ducke, Manaus (AM); breu sucuruba (Trattinickia buserifolia) - Belterra (PA); cuiarana de caroço (Buchenovia huber) - Belterra (PA); sumaúma (Ceiba pentrandra) - CPAA (AM); cupuaçu (Theobroma grandiflorum) - coleção do CPAA, Manaus (AM); cacau (Theobroma cacao) - feira livre - Manaus (AM); beribá (Rollinia mucosa) - feira livre - Manaus (AM); sorva (Couma spp) banco de germoplasma do INPA, Manaus (AM); pupunha (Bactris gasipaes) - banco de germoplasma do INPA, Manaus (AM); açai (Euterpe spp) - feira livre, Belém (PA) e arredores do CPAA, Manaus (AM); e camu-camu (Myrciaria paraensis) - banco de germoplasma do INPA, Manaus (AM).

A posição que cada espécie ocupa no modelo idealizado, constitui uma tentativa de representar o nível de tolerância à sombra que as plantas suportariam em condições naturais. Admite-se que o sucesso do modelo, como um método de conservação ex situ de recursos genéticos na região, está inteiramente relacionada à representação das características básicas das espécies responsáveis pela manutenção do equilíbrio biológico.

Por isso, está previsto a aplicação de todos os tratos culturais inerentes a cada espécie, visando oferecer as melhores condiçōes de crescimento para as plantas. Após três anos de implantado o modelo, esses tratos culturais serão suspensos, objetivando o restabelecimento da flora e da fauna locais.

Outra alternativa de recomposição da flora do extrato inferior é fazer o enriquecimento do sub-bosque com espécies de valor econômico, atual ou potencial, que comprovadamente sejam tolerantes à sombra. $\mathrm{O}$ enriquecimento pode também ser feito com espécies anuais de propagação vegetativa, com alto risco de erosão genética ou mesmo em processo de extinção, que perfeitamente sobrevivem nessas condições, como por exemplo, o ariá (Calathea allouia).

Está previsto avaliações anuais de caracteres morfológicos em todas as plantas, com o objetivo de medir a sobrevivência, adaptação e capacidade da espécie em deixar descendentes. Será feito também o registro da ocorrência e intensidade de ataque de pragas e doenças.

A viabilidade técnica e econômica do método de conservação será feita, preliminarmente, após 5 anos da implantação. O sucesso dependerá da ocorrência e viabilidade da floração e frutificação das espécies. A avaliação definitiva será feita após os 10 anos.

Justifica-se a necessidade de efetuar essa avaliação preliminar, pela urgência em retomar as coletas de germoplasma de espécies autóctones sob risco de erosão genética. Esta pesquisa constitue a primeira etapa de um programa mais abrangente sobre coleta e conservação de germoplasma de espécies autóctones de valor econômico, atual e potencial, cuja a conservação seja feita na forma de coleções de plantas mantidas a campo.

\section{Manutenção de Coleções em Áreas de Produtores}

A discussão do método de conservação proposto culminou na formulação de nova hipótese de pesquisa, 
em que considera a viabilidade de testar a conservação da variabilidade genética de espécies de reconhecido valor econômico, em áreas de pequenos produtores.

A hipótese é sustentada no fato de que os pequenos produtores da região, normalmente mantém pequenos plantios ao redor de suas casas constituído por uma miscelânea de espécies. A distribuição na área é feita aleatoriamente, com predominância de espécies que produzem produtos comestíveis, principalmente fruteiras. Esses plantios são comumente denominados de "quintais" e, praticamente, o único trato cultural que recebem é de redução da concorrência com ervas daninhas.

A introdução de variabilidade em pequenos plantios domésticos talvez não seja atraente do ponto de vista do produtor, pois isso pode determinar menor produtividade. Todavia, a conservação da variabilidade genética de espécies, as quais são de interesse dos pequenos produtores, pode ser viabilizada. Basta que se tome, como unidade amostral, as comunidades desses produtores e que a distribuição dos materais de plantio seja orientada para que cada produtor receba somente parte dessa variabilidade.

A probabilidade do pequeno produtor em manter no seu quintal, germoplasma de espécies perenes de valor alimentício, principalmente de fruteiras regionais, é inversamente proporcional a quantidade devariabilidade genética existente na amostra. Naturalmente, $o$ produtor eliminará as plantas que não fornecem algum tipo de fruto, àquelas que apresentem características desfavoráveis ao plantio, ou àquelas que não sejam de sua preferência.

A quantidade de variabilidade genética mantida em pequenas propriedades distribuídas em determinado município, quando juntas, pode representar uma soma considerável de variação. A conservação de recursos genéticos utilizando-se desse procedimento, teria como vantagens a garantia de sustentabilidade dos quintais em relação ao meio ambiente, atividade de custos mais reduzido do que mantido sob outras formas, acesso a informação do comportamento preliminar do material conservado e acesso fácil na obtenção de amostras de sementes. Para tanto, são necessários o controle sobre a identificação e distribuição do material, desde a coleta até o plantio definitivo.

Esse método precisa ser testado, inicialmente, para as espécies coletadas pelos órgãos de pesquisa e mantidas em banco de germoplasma. A experiência tem demonstrado que a conservação da variabilidade genética das espécies, em forma de coleções mantidas em campo, na região tropical, além de ser um método bastante oneroso, provoca o desequilíbrio do meio ambiente e, normalmente, com algumas exceções, não tem alcançado o sucesso desejável.

\section{CONCLUSÕES}

No esquema tradicional de conservação de recursos genéticos de plantas na região, o qual inclui coleta, conservação, avaliação, caracterização e utilização, normalmente, tem sido executado com certa eficiência somente a fase de coleta. A avaliação e caracterização é prejudicada à 
medida que aumente a ocorrência de pragas e doenças, devido não disporse de metodologias de conservação que minimizem esses efeitos. Consequentemente, a fase de utilização da variabilidade coletada é, quase que totalmente, prejudicada por esses motivos e pela baixa demanda dos programas regionais de melhoramento.

A constatação do pouco conhecimento existente sobre o nível de variabilidade genética em populações naturais de plantas, revela uma grande falta de preocupação com os ecossistemas tropicais, considerando o seu potencial agrícola e florestal.

As possibilidades de perdas significantes de variabilidade genética, causadas pela atividade humana, principalmente devido à destruição de habitats naturais de populações de plantas, destaca a importância das pesquisas e dos procedimentos adotados na prática de conservação dos recursos genéticos no ecossistema tropical.

A falta de metodologias adequadas de conservação, serve de justificativa para não incrementar a coleta de germoplasma na região, auxiliada pela baixa demanda por nova variabilidade genética dos programas regionais de melhoramento. A perda de variabilidade de populações de espécies autóctones, devido a ação antrópica, sai menos dispendiosa do que aquelas que, naturalmente, ocorre nos bancos de germoplasmas instalados na região, em consequiência do desequilíbrio biológico provocado pelo método de conservação.

É importante destacar esses pontos para que se faça uma abordagem mais crítica do problema. Como não dispõese de metodologias de conservação adequadas às condições tropicais, a pesquisa tem que rapidamente buscar respostas a esses questionamentos, sob risco de perdas irreparáveis.

Atualmente, os mais interessados em coletar variabilidade genética de espécies autóctones são os grupos estrangeiros, por conta das demandas dos seus programas de melhoramento genético. Provavelmente, na conservação de germoplasma efetuada fora da região estes problemas são minimizados.

Os estudos de avaliação dos padrões de distribuição da variabilidade muito contribuirão para o discernimento, do que e de como conservar, evitando com isso manter grandes coleções de plantas, representando pouca variabilidade. Ou mesmo, realizar grandes coletas de germoplasma, a custos elevados para, logo a seguir, ocorrer a destruição das coleções em campo, causada pelos condicionantes biológicos.

À medida em que forem obtidas informações consistentes sobre o nível e a distribuição da variabilidade genética nas populações naturais, tornar-se-á necessário conhecer também às relações desses parâmetros com a adaptação e sobrevivência das espécies.

Os programas de melhoramento genético de espécies tropicais serão fortalecidos, com os conhecimentos das estratégias utilizadas pelas espécies para manterem-se em equilíbrio com o meio ambiente, podendo sugerir mudanças nos atuais sistemas de cultivo. Além disso, a 
manutenção de banco de genes facilitará a incorporação de características superiores nas novas cultivares obtidas.

$\mathrm{O}$ incentivo à pesquisa sobre métodos de conservação ex situ de espécies tropicais, sem dúvida, constitui-se em outro caminho que facilitará o desenvolvimento de altemativas para manter coleções de plantas em campo, além de contribuír para aumentar o conhecimento científico desse ecossistema.

A experiência tem demonstrado que para ter êxito, o método de conservação ex situ na região tem que ser sustentável em relação ao meio ambiente e apresentar baixo custo operacional. Em princípio, essa metodologia pode prejudicar a fase de avaliação ou caracterização dos acessos. É mais sensato hoje pensar em conservar a variabilidade antes que desapareça e, futuramente, avaliar o potencial de espécies previamente identificadas como de valor econômico.

\section{Bibliografia citada}

ALBUQUERQUE, M. de; LIBONATI, V.F. 1964. IPEAN: 25 anos de pesquisa na Amazônia: histórico, organização, pesquisa. Belém. IPEAN, p.84.

ALLARD, R.W. 1971. Princípios do melhorcunento genético de plantas. São Paulo, Edgard Blucher. 382p.

AOKI, H.; SANTOS, J.R. 1982. Características dos estratos arbustivo e arbóreo do Distrito Federal. Silvicultura en SãoPaulo, 16A(1);629-639.

BAKER, H.G, 1959. Reproductive methods as factors in speciation in flowering plants. Cold Spring Harbor Quantitative Biolog!; 24:177191.

BAKER, H.G. 1965. The evolution of the cultivated
Kapok trees: aprobable West African product. In: D. Brokensha, (ed.). Ecology and economic development in tropical Africa. Institute of International Studies, Berkeley, University of California, p.185-216.

BAKER, H.G. 1978. Chemical aspects of the pollination biology of woody plants in the tropics. In: B.P. Tomlinson \& M.H. Zimermann (eds.). Tropical trees as living systems, Cambridge, p.57-82.

BAKER, H.G;; BAWA, K.S.; FRANKIE, G.W.; OPLER, P.A. 1983. Reproductive biology of plants in tropical forests. In: F.B. Golley (ed.). Tropical rain forest ecosystens. Amsterdan, p.183-214.

BAITELLO, J.B.; AGUIAR, O.T. 1982. Flora arbórea da serra da Cantareira (São Paulo). Silvicultura em São Paulo, 16A(1):582-590.

BARRIGA, J.P; MACHADO, P.FR.; ALMEIDA; C.M.V.C.; ALMEIDA, C.F.G. 1984. Preservação e utilização dos recursos genéticos de cacau na Amazônia hrasileira. Illhéus, Comissão Executiva do Plano da Lavoura Cacaueira. 38p. (Comunicado Técnico Especial, no. 5).

BAWA, K.S. 1974. Breeding systems of tree species of a lowland tropical community. Evolution, 28:85-92.

BAWA, K.S.; OPLER, P.A. 1975. Dioecism in tropical trees. Evolution, 29:167-179.

BAZZAZ F.A.; PICKETT, S.T.A. 1980. Phyollogical ecology of tropical succession: a comparative review. Annals Revue Ecological Systtems, 11:283-310.

BOUVAREL, P. 1970. The conservation of gene resources of forest trees, $I n:$ O.H. Frankel \& E. Bennett (eds.). Geneticis in plantstheir exploration and conservation. Blackewell Scienfic Publications. p.523-529.

BROWN Jr, K.S. 1987. O papel dos consumidores na conservação e no manejo de recursos genéticos florestais in situ. IPEF, 35:61-69.

BUDOWSKI. A. 1965. Distribution of tropical american rain forest species in the light of successional progresses. Tumialha, 15:40-42.

CATHARINO, E.; CRESTANA, C.S.M. \& KAGEYAMA,PY. 1982. Biologia floral da 
bracatinga - Mimosa scabrella Benth. Silvicultura em São Paulo, 16(1):35-38.

CLEMENT, C.R.; MULLER, C.H.; FLORES, W.B.C. 1982. Recursos genéticos de espécies frutíferas nativas da Amazônia brasileira. Acta Amazônica, 12(4):677695.

CRESTANA, C.S.M.; DIAS, I.S.; KAGEYAMA, P.Y. 1983. Biologia floral do guarantã (Esenbeckia leiocarpa Engl.). Silvicultura, 8(28):35-38.

CRESTANA, C.S.M.; DIAS, 1.S; MARIANO,

G. 1983/85. Ecologia de

polinização de Hymenaea stilbocarpa Hayme, o jatobá. Silvicultura em São Paulo, 17/19:31-7.

FAEGRI, K.; PIJL, L. van der. 1976. The principles of pollination ecology Oxford, Pergamon Press. p291.

FEARNSIDE, P.M. 1986. Spatial concentration of deforestation in the Brazilian Amazon. Ambio, 15(2):74-81.

FEDOROV, A.A. 1966. The structure of the tropical rain forest and speciation in the humid tropics. Journal Ecology, 54:1-11.
FRANKIE, G.W.; OPLER.; BAWA, K.S. 1976. Foraging behavior of solitary bees: implications for outcrossing of a neotropical forest tree species. Journal Ecology, 64:1049-1057.

GAN, Y.Y.; ROBERTSON, F.W.; ASHTON, P.S.; SOEPADMO, E.; LEE, D.W. 1977. Genetic variation in wild populations of rain forest trees. Nature, 269:323.

GOMEZ-POMPA, A. 1971, Possible papel de la vegetacion secundaria en la evolución de la flora tropical. Biotropica, 3:125135.

GOMEZ-POMPA. A.; VASQUEZ-YANES, C.; GUEVARA, S. 1972. The tropical rain forest: a nonrenewable resource. Science, 177:762-765.

HAMRICK, J.L. 1983. The distribution of genetic variation within and among natural plant populations. In: SchonewaldCox; C.M.; Chambers, S.M.; W.L. Thomas, (eds.). Genetic and Conservation, Menlo Park, The Benjamin/Cumnings. p335-348. 